\title{
A Family of Juvenile Idiopathic Arthritis: Case Report
}

\author{
SYED SHAFI AHMED MUAZ ${ }^{1}$, SHAMIM AHMED SHAMIM ${ }^{2}$, SALIM AHMED ${ }^{3}$ \\ MUSAMMATH MORIOM SIDDIKA ${ }^{4}$, BISHWAJIT DEB ${ }^{5}$
}

\section{Introduction}

Juvenile idiopathic arthritis (JIA) is arthritis of unknown etiology that begins before the 16th birthday and persists for at least 6 weeks; other known conditions are excluded ${ }^{1}$. JIA is a complex genetic trait. Despite the genetic contributions to disease risk observed in many case-controls studies, familial JIA is rare ${ }^{2}$. The level of risk to family members of a JIA proband appears to be relatively low as compared with other autoimmune diseases ${ }^{3-5}$. Because no one gene or mutation is sufficient to result in disease, but must interact with one or more other genetic factors, the probability of disease occurring in more than one family member is relatively low? ${ }^{2}$.

Published reports of multiplex families have been limited. Earlier reports of families with multiple affected members involved twins, affected sibpairs (ASPs), and parent-child combinations, indicating that they are likely to be the most common forms of familial disease $e^{6-8}$. In the present study, a family is described in which the incidence of JIA was demonstrated in three out of four siblings, the parents being not related.

\section{Case Report}

Case-1: A 9 years old boy of nonconsanguinous parents was admitted with history of painful swelling of both knee joints followed by swelling of both elbow joint and gradually involving small joints of hand and feet for last 2 years. Then deformity of small joints of hand and feet accompanied by pain for last 6 months. On examination, the child was wasted, afebrile with tender swelling of both wrist and knee joint along with flexion deformity of both elbow joint, proximal interphalangeal joints of hand and feet excepting great toe (Fig.-1). Rest of the examination including ocular findings were normal, bed side urine for albumin was nil, no lymphadenopathy, hepatosplenomegaly and skin rash. Investigation showed haemoglobin of 12.4 $\mathrm{gm} / \mathrm{dl}$, total leukocyte count of $12.4 \times 10^{9} / \mathrm{L}$ with a differential count of neutrophil $69 \%$, lymphocyte $20 \%$, monocyte 02\%, eosinophil 09\%. ESR $30 \mathrm{~mm}$ at the end of 1 hour. Peripheral blood film suggested leucocytosis, c-reactive protein $6 \mathrm{mg} / \mathrm{L}$. Rheumatoid factor and antinuclear antibody (ANA) were negative. HLA typing (Class-I) revealed: A Locus A9(24), A19(33); B Locus B12(44), B15(62); C Locus CW-, CW-; others
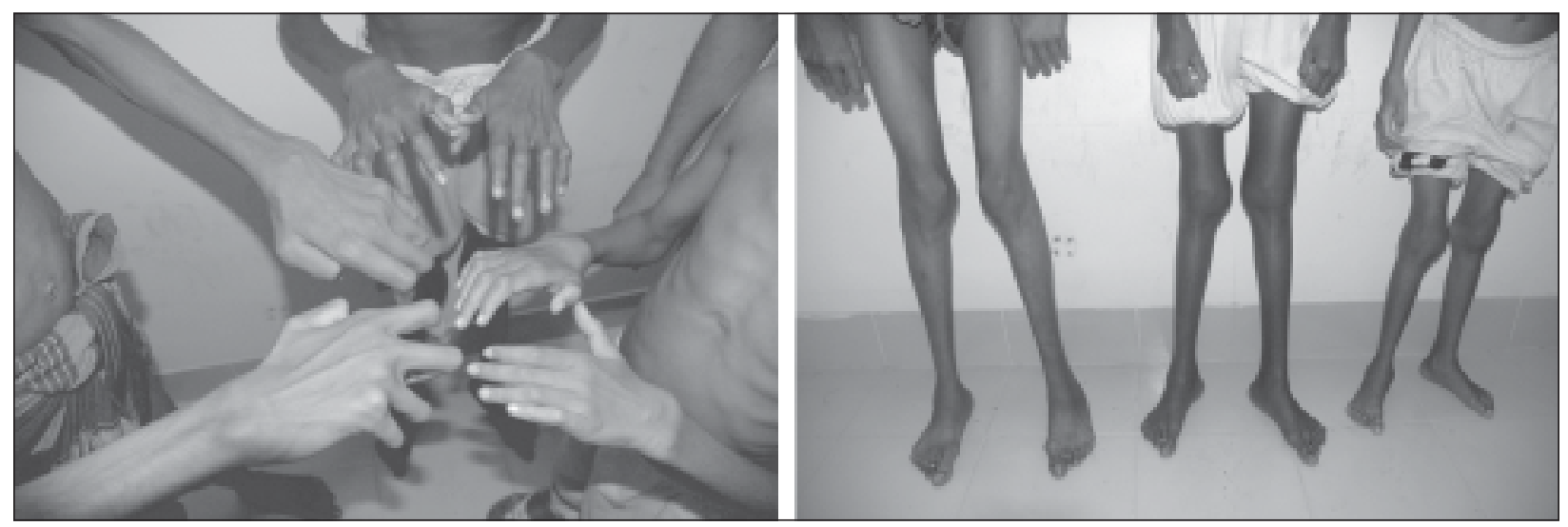

Fig-1: Clinical findings of hands and feet

1. Associate Professor and Head, Department of Paediatrics, Jalalabad Ragib-Rabeya Medical College Hospital, Sylhet

2. Assistant Professor, Department of Paediatrics, Jalalabad Ragib-Rabeya Medical College Hospital, Sylhet

3. Assistant Professor, Department of Pharmacology, Jalalabad Ragib-Rabeya Medical College Hospital, Sylhet

4. Assistant Registrar, Department of Paediatrics, Jalalabad Ragib-Rabeya Medical College Hospital, Sylhet

5. Indoor Medical Officer, Department of Paediatrics, Jalalabad Ragib-Rabeya Medical College Hospital, Sylhet

Correspondence: Dr. Syed Shafi Ahmed
BW4, Bw6. X-ray knee joint showed soft tissue swelling and X-ray wrist joint showed osteoporotic changes in the epiphysis of the lower end of radius and ulna in both side with deformity of the metacarpophalangeal joints of thumb, also deformity in the proximal interphalangeal joints of other fingers with marked soft tissue swelling around the joint spaces (Fig.-2a). During the course of the disease he was left untreated and gives the occasional history of 

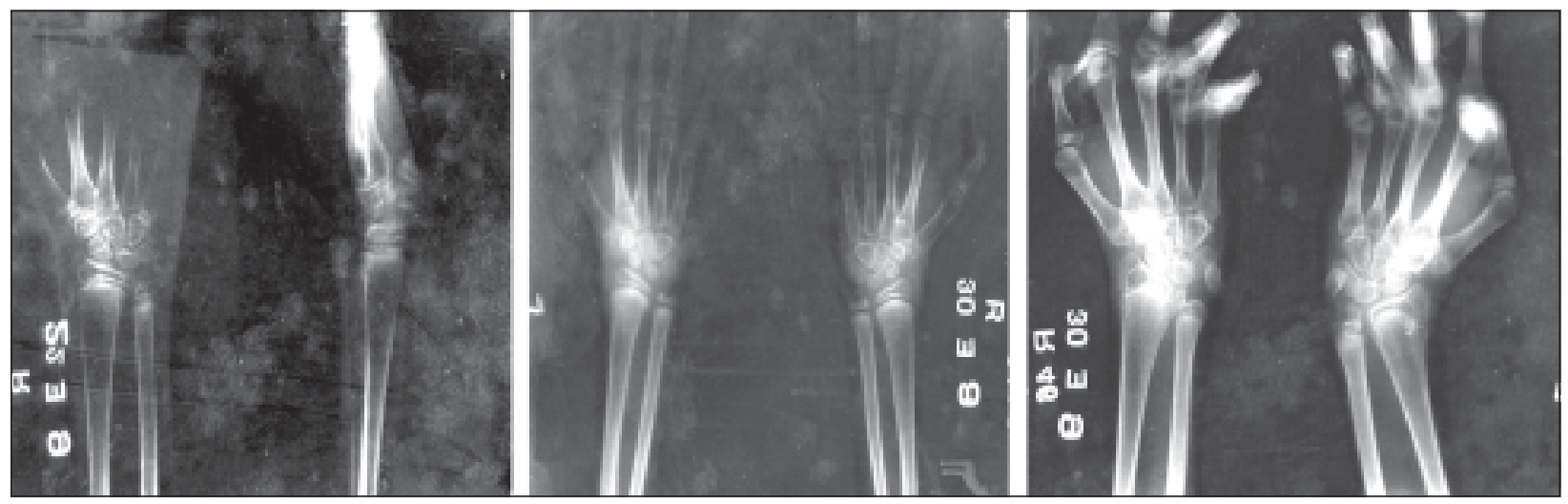

Fig-2: Radiological findings of hands joints of three cases

intaking of some analgesic and antipyretics according to need. On admission to hospital he was started treatment with aspirin, methotrexate and partially responded.

Case-2: A 13 years old boy, first showed the symptoms of the disease at the age of 5 years with painful swelling of knee, elbow and ankle joint. Then deformity of small joints of hand and feet developed at the age of 11 years along with pain and restriction of movement. On examination, the child was wasted, afebrile with tender swelling of both wrist and knee joint along with flexion deformity of proximal interphalangeal joints of all fingers, toes and distal interphalangeal joint of index finger but extension of distal interphalangeal joint of other finger and all toes. Rest of the examination revealed normal. Investigation showed haemoglobin of $11.7 \mathrm{gm} / \mathrm{dl}$, total leukocyte of $12.1 \times 10^{9} / \mathrm{L}$ with a differential count of neutrophil $70 \%$, lymphocyte $25 \%$, monocyte $02 \%$, eosonophil $03 \%$. ESR $40 \mathrm{~mm}$ at the end of 1 hour. Peripheral blood film suggested neutrophilia, c-reactive protein $6 \mathrm{gm} / \mathrm{dl}$. Rheumatoid factor and ANA were negative. HLAtyping, X-ray knee joints and wrist joints (Fig.-2b) was almost similar to case 1. During the course of the disease he was also left untreated as like as case 1. On admission to hospital he could not respond with aspirin, methotrexate and later needed steroid therapy in addition.

Case-3: A 15 years old boy showed painful swelling of knee and elbow joints. At the age of 5 years, then gradually developed wasting of hand and leg muscles. After that deformity of small joints of hand and feet along with pain and limitation of movement at the age of 13. On examination the child was wasted, afebrile with tender swelling of both knee joint, flexion deformity of both elbow joint, 'button hole deformity' of fingers of both hand. Flexion of proximal interphalangeal joint and extension of distal interphalangeal joint of all toes. Other examination revealed normal.

Investigation showed $\mathrm{Hb}$ of $12 \mathrm{gm} / \mathrm{dl}$, total leucocyte count of $8,800 /$ cumm, with a differential count of neutrophil $61 \%$, lymphocyte $26 \%$, monocyte $04 \%$, esonophil 09\%. ESR $30 \mathrm{~mm}$ at the end of $1^{\mathrm{st}} \mathrm{hr}$, ASO titre $<200 \mathrm{IU} / \mathrm{ml}$. Rheumatoid factor and ANA were negative. Reports of HLA-typing was similar to case1 $\&$ case 2 . Findings of $x$-ray knee joints showed soft tissue swelling and wrist joint showed increased thickness of the epiphysis of the lower end of radius and ulna with osteopenia of the epiphysis and metacarpal bones with soft tissue swelling around the wrist joint, flexion deformity of the metacarpophalangeal joint and deformity is also seen in the interphalangeal joints (Fig.-2C). He was treated with NSAID's for last 4 months, but there was no reasonable improvement and finally treatment started with aspirin and also methotrexate and partially responded. The parents and 1 sibling aged 11 years were healthy with no specific complaints or findings.

\section{Discussion}

Both clinical symptoms and radiological studies in the three siblings were compatible with polyarticular onset of JIA. The specific feature is the appearance of the disease in three out of four children in the same family. One child aged 11 years old have no symptoms of the disease. So far as we found such a greater incidence in one family has not been described in the literature in Bangladesh till now. Our patients presented with swelling and deformity of joint along with pain and limitation of movement. No iritis, anemia, fever, rash, lymphadenopathy and hepatosplenomegaly 
could be demonstered in any of them. Swelling started in the knee joints and gradually involved other joints. Muscular wasting was found in all of the three children.

Similar type of familial occurrence was reported by Yodfat et $\mathrm{al}^{9}$ but there is some variation of clinical features and laboratory findings from our study. Their study showed five siblings out of seven children suffered from monoarticular onset and oligoarthritic course of JIA. But our patients presented with polyarticular type of JIA. The most prominent feature was painful swelling of both knee joint along with deformity of small joints of both hand and feet with characteristic radiological changes.

An interesting observation was that the clinical features and laboratory findings were almost similar in all of the three children. In complete blood count one children showed leucocytosis, one children showed neutrophilia and two showed eosinophilia, raised ESR, and positive rheumatoid factor and ANA were negative in all of the three children but c-reactive protein was positive. Reports of HLA typing (Class-I) provides the assumption that genetic factors may play a part in the aetiology of the disease.

The cumulative incidence of the disease in three members of the same family would justify the assumption of a familial predisposition, perhaps genetically determined in the aetiology of juvenile idiopathic arthritis.

\section{References}

1. International League of Associations for Rheumatology Classification of Juvenile
Idiopathic Arthritis: Second Revision. The Journal of Rheumatology, Edmonton 2001: 390-92.

2. Glass DN, Giannini EH. Juvenile Rheumatoid Arthritis as a complex genetic trait. Arthritis and Rheumatism, American College of Rheumatology 1999; 42: 2261-68.

3. Risch N. Linkage strategies for genetically complex traits. I. Multilocus models. Am J Hum Genet 1990; 46: 222-28.

4. Risch N. Linkage strategies for genetically complex traits. II. The power of affected relative pairs. Am J Hum Genet 1995; 57: 911-19.

5. Seldin MF, Amos Cl, Ward R, Gregersen PK. The genetics revolution and the assault on rheumatoid arthritis. Arthritis Rehum 1999; 42: 1071-79.

6. Baum J, Fink C. Juvenile rheumatoid arthritis in monozygotic twins: a case report and review of the literature. Arthritis Rheum 1968; 11: 33-36.

7. Rosenberg AM, Petty RE. Similar patterns of juvenile rheumatoid arthritis within families. Arthritis Rheum 1980; 23: 951-53.

8. Clemens LE, Albert E, Ansell BM. Sibling pairs affected by chronic arthritis of childhood: evidence for a genetic predisposition. J Rheumatol 1985; 12: 108-13.

9. Yodfat Y, Yossipovitch Z, Cohen I, Shapira. A family with a high incidence of Juvenile rheumatoid arthritris. Ann Rheum Dis 1972; 31: 92-94. 